\title{
EFFECT OF CHITD BEHAVIOR ON THE INTEMAL SPACES OF KINDERGARTENS
}

\author{
Abdulhafeez Ahmad M. Alwafi \\ Architecture and interionr desingn, College of Enmgineering and Islamic Architecture, \\ Department of Islamic Architecture, Saudia Arabia
}

\begin{abstract}
At present, there is a great development in various fieldsof life;these developments included the development of children's needs and behavior, Where it became necessary to provide the appropriate educational environment that meets the requirements of children of the new age, Therefore, the current research has been prepared to identify the extent to which the children's behavioris affected by the internal spaces of the kindergarten building,to highlighting the importance of readiness of kindergartens in the development of different skills in children,and to identify the most important specifications and architectural standards that must be available in kindergartens. To achieve the objectives of this research was used descriptive approach by looking at the facts and literature and previous studies that relate to the subject of the current research. The results of this research showed that there are many specifications and standards that must be available in kindergartens buildings; Such as the building must be in a healthy area with sunlight and open air, it should be far from industrial areas, markets and congestion places, and Avoid obstructions such as columns and barriers in the indoor space of kindergartens.
\end{abstract}

Keywords: children, kindergartens, requirements, building, spaces, b ehavior.

$$
\begin{aligned}
& \text { تأثير سلوك الطقل على الفراغات الداخلية لرياض الأطفال }
\end{aligned}
$$

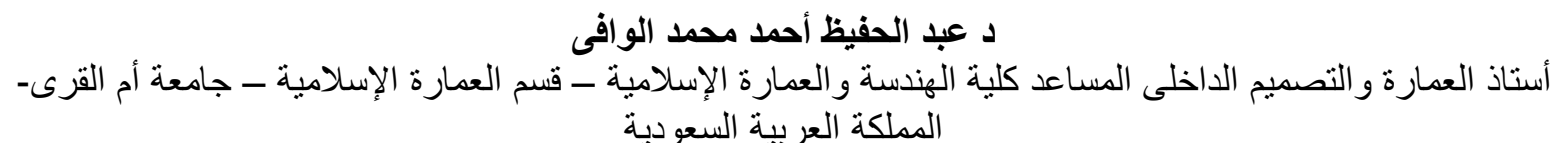

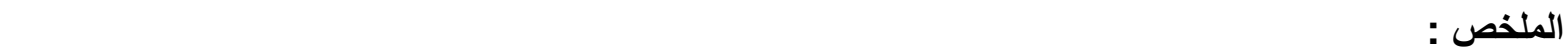

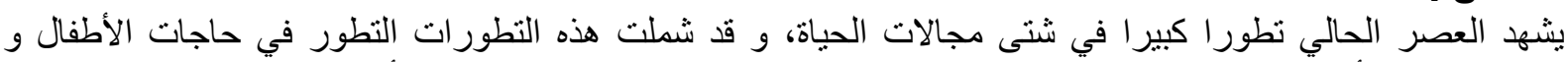

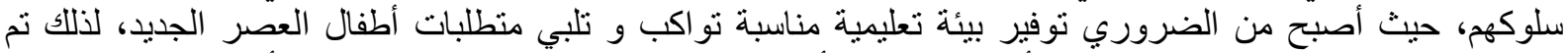

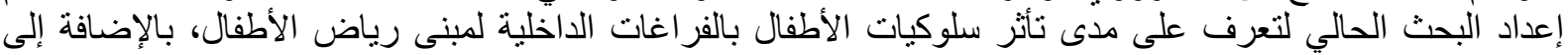

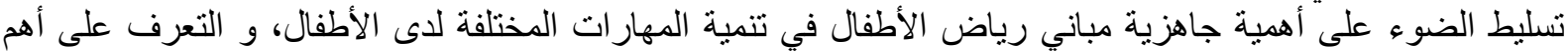

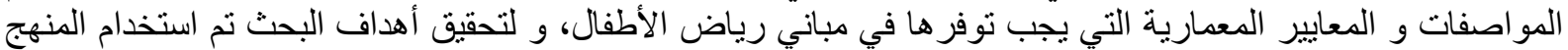

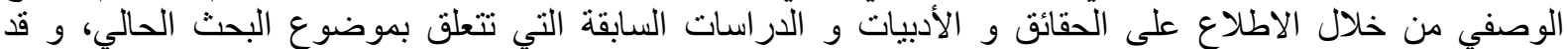

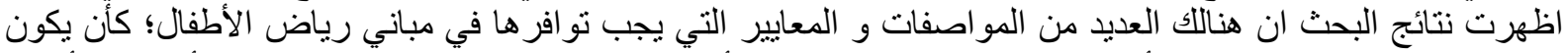

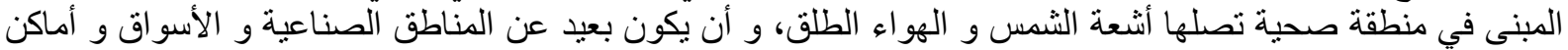

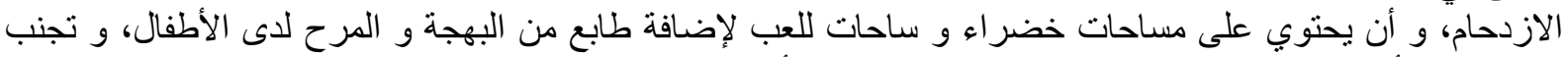

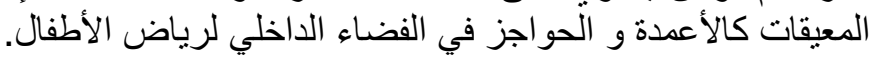

$$
\text { كلمات مفتاحية: الأطفال، رياض الأطفال، المواصفات، المبنى، الفراغات، السلوك. }
$$




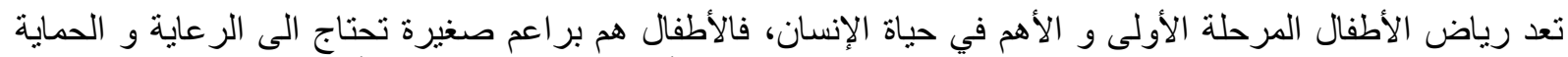

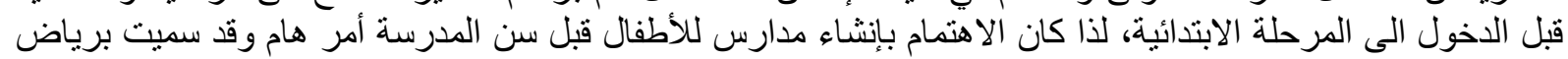

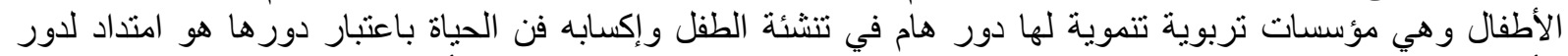

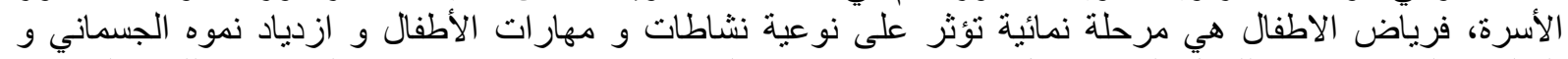

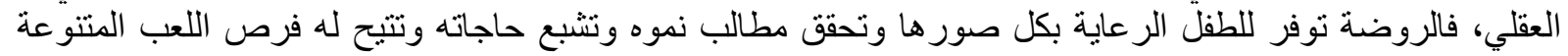

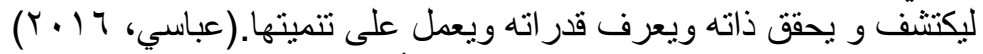

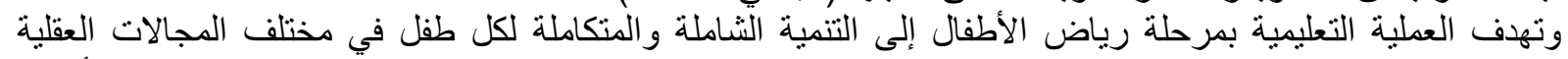

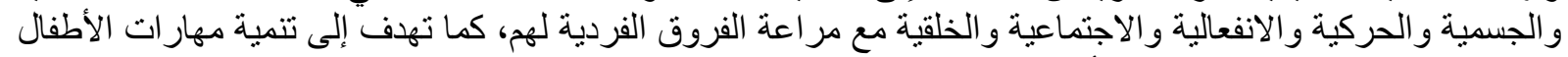

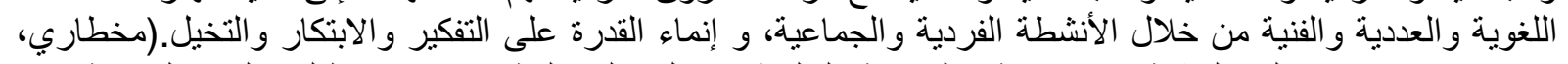

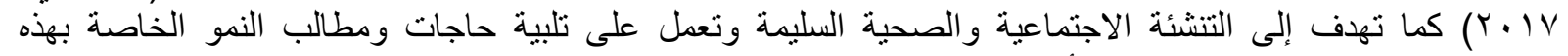

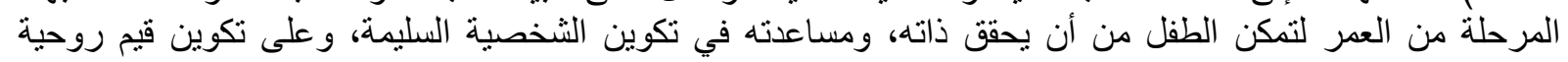

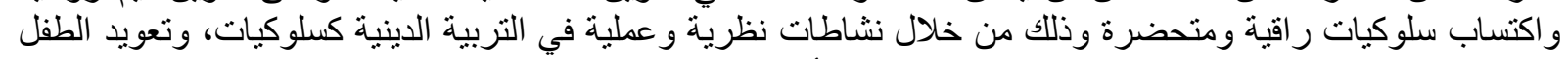

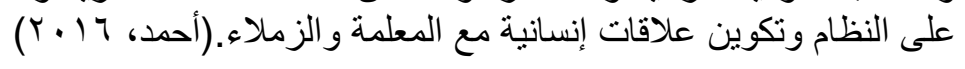

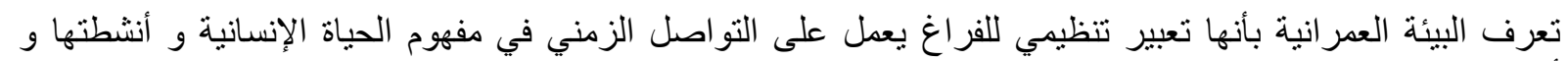

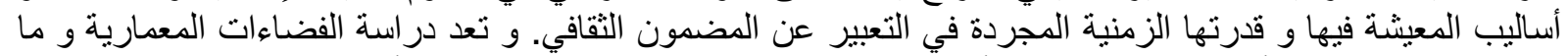

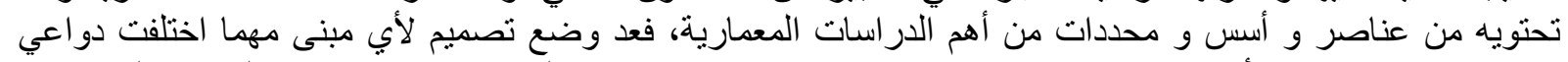

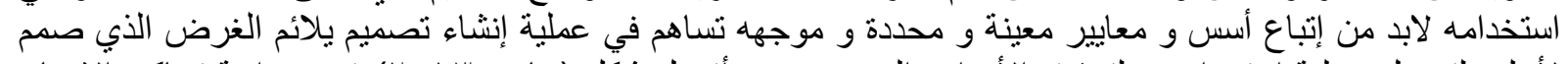

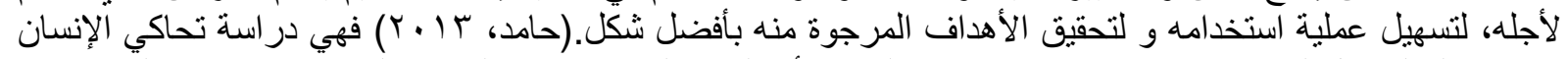

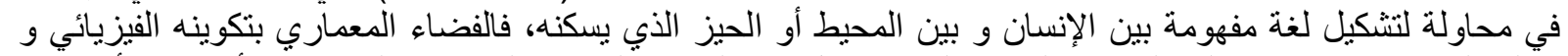

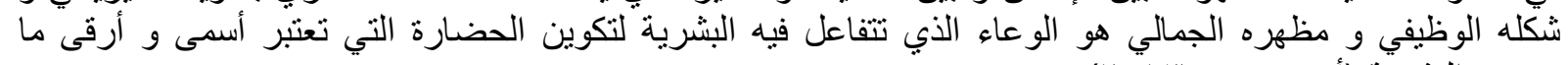

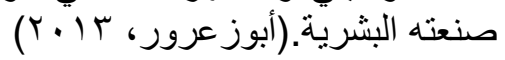

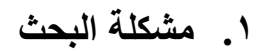

اهتمت العديد من الذراسات و الأبحاث بدور رياض الأطفال في تتمية العديد من المهار ات و القدرات لاتى الأى الأطفال، سواء

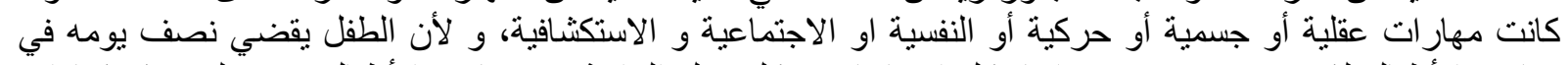

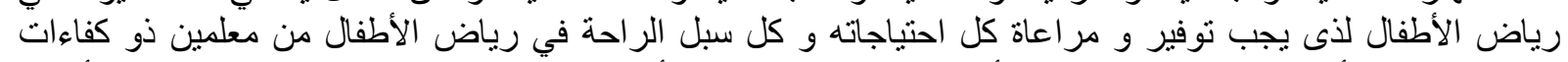

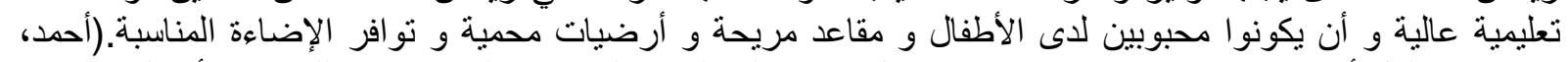

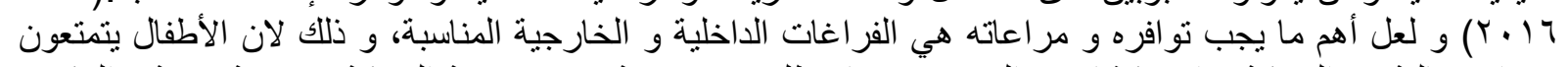

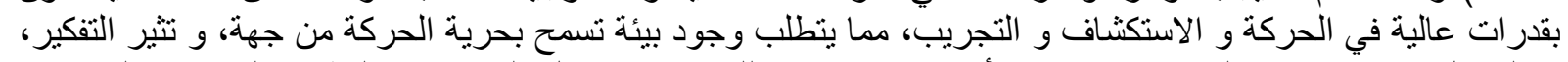

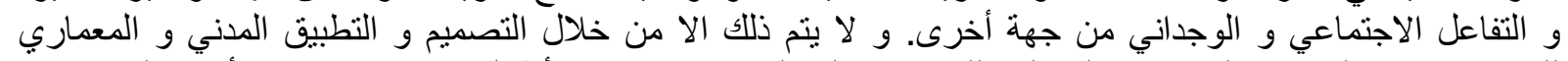

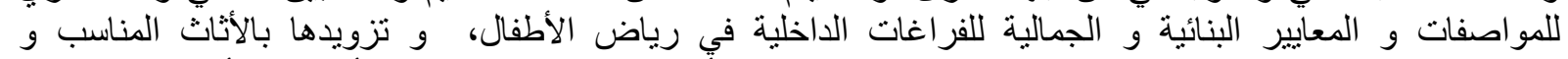

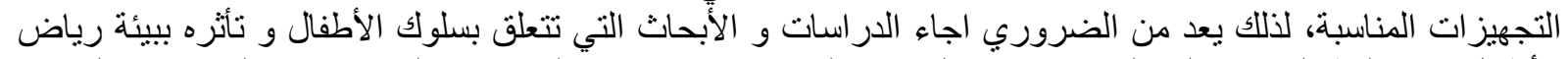

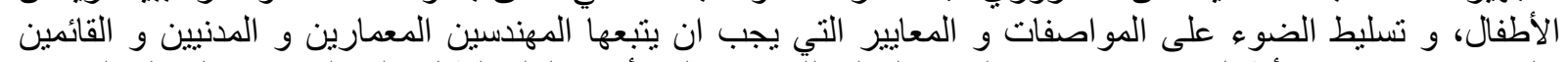

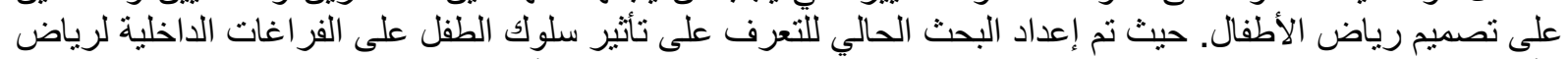
الأطفال، و التعرف على المى المواصفات و المعايير التي يجب توافي لافرها في رياض الأطفال لتحقيق الغاية من وجودها.

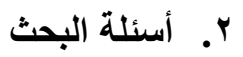

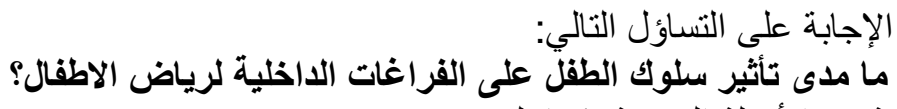
تركز الورقة البحثية حول الإجابة على التساؤل التالي:

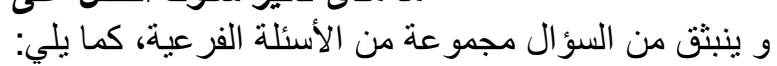

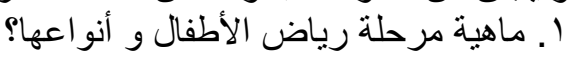

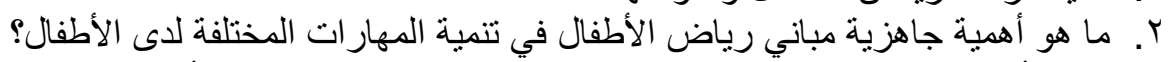

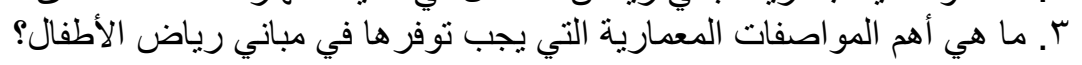




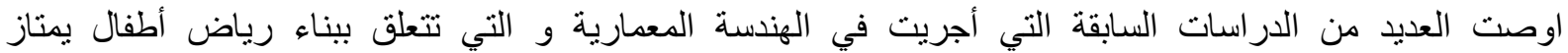

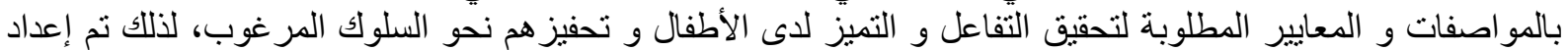
الورقة البحثية لتحقيق الأهداف التالية:

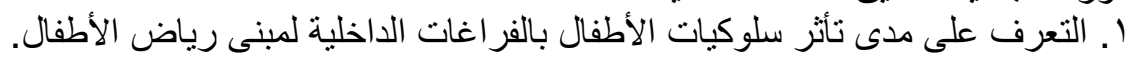

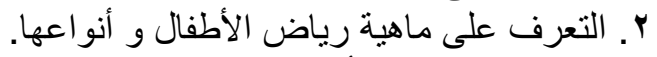

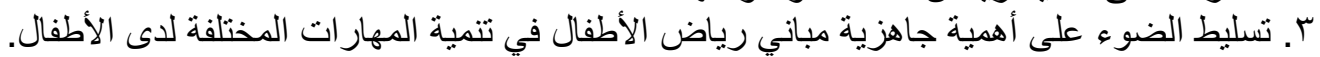

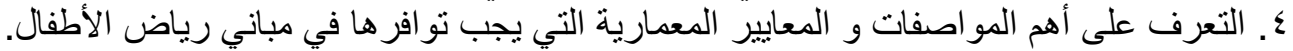

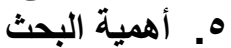

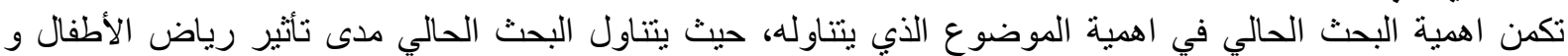

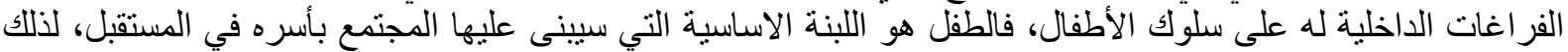

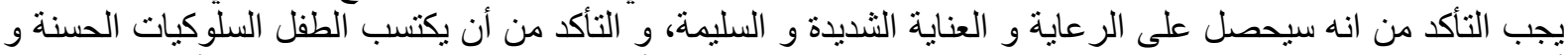

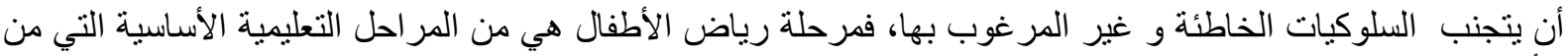

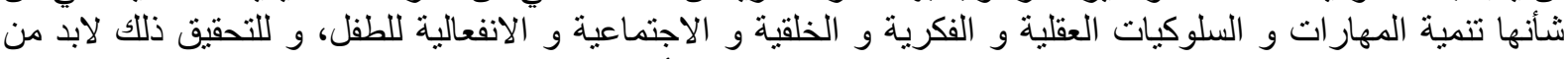

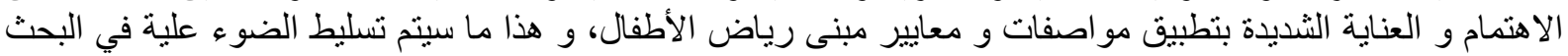

هاءت هذه الجزئية من الدراسة لإعطاء تصور عام عن أهم المفاهيم و المحتوى النظري الذي يُعرِّف الدراسة ومصطلحاتها كما يلي:

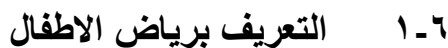

تعرف رياض الأطفال( Preschool) بأنها مؤسسات اجتماعية تقدم الرعاية النهارية للأطفال الذين ينتمون الى المرحلة

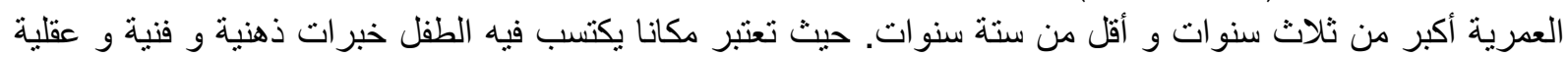

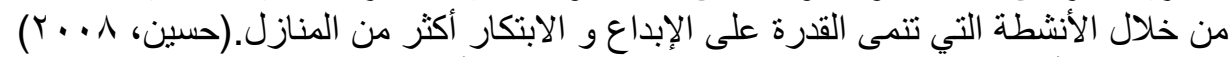

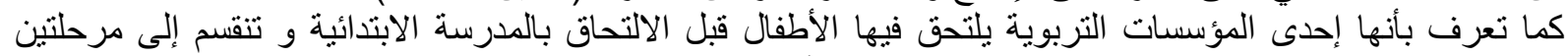

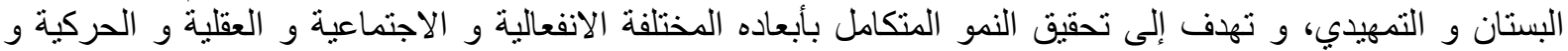

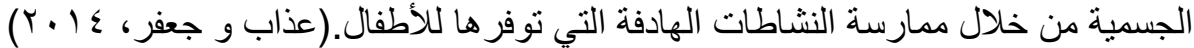

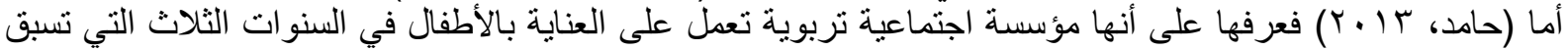

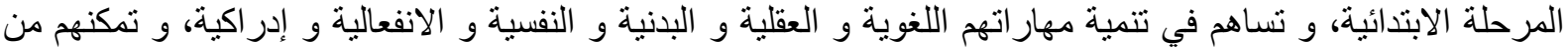

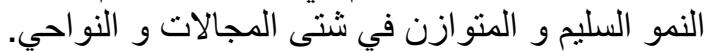

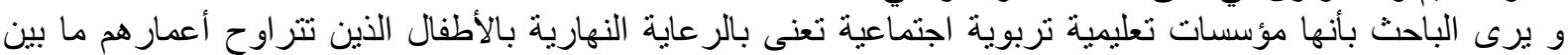

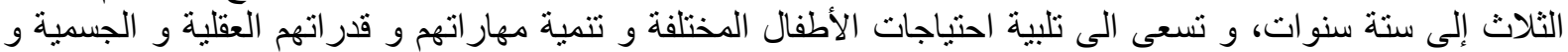

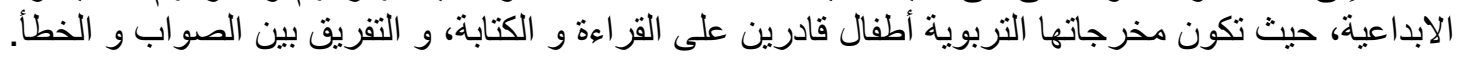

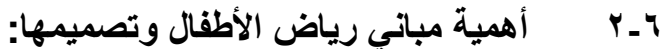

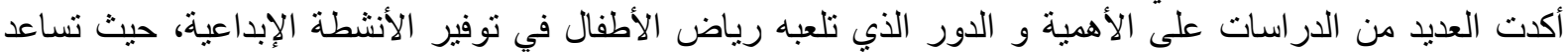

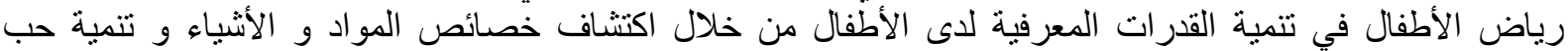

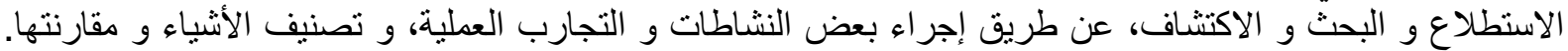

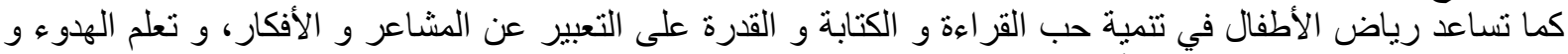

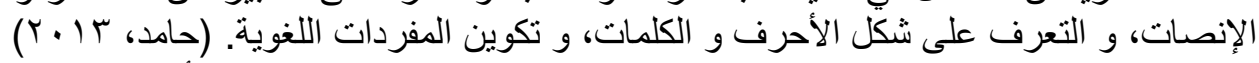

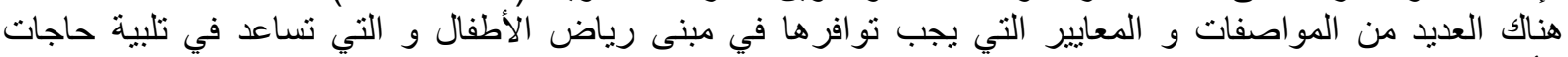

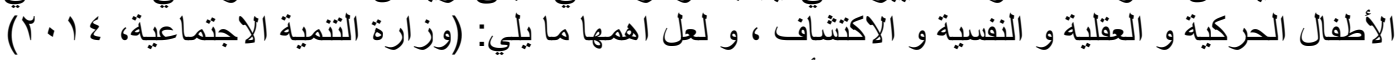

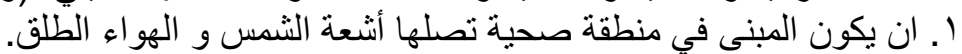

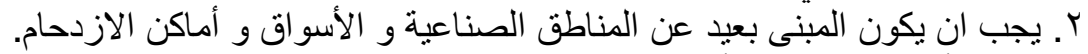

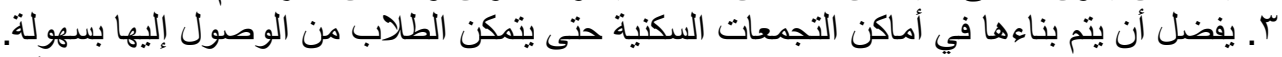

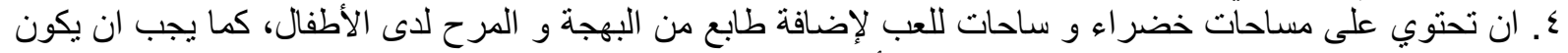

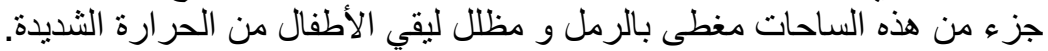

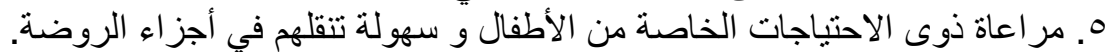

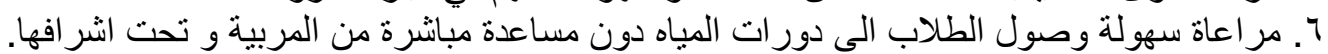

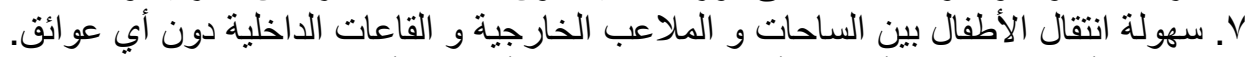
^. نوفير الأماكن الخاصة بأولياء الأمور لسهولة الملاع جلب الأطفال و أخذهم. 
9. تجنب المعيقات كالأعمدة و الحواجز في الفضاء الداخلي لرياض الأطفال.

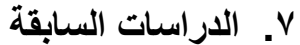

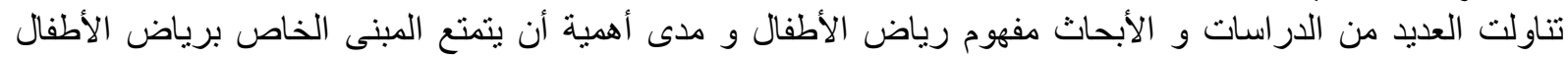

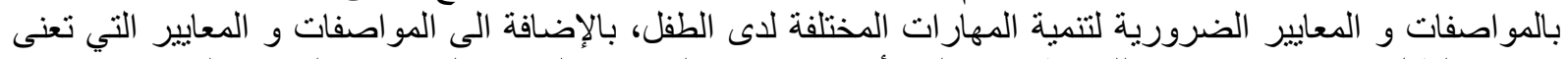

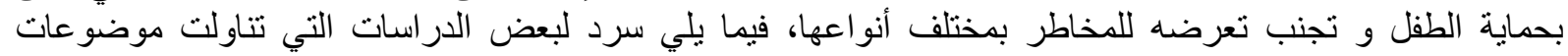

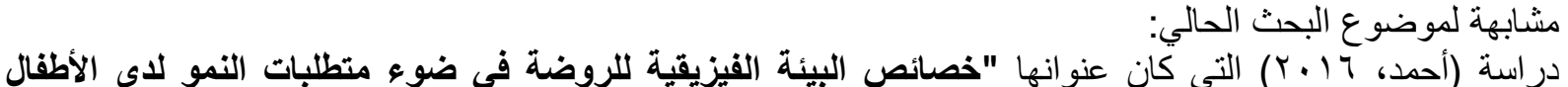

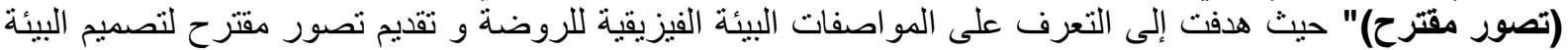

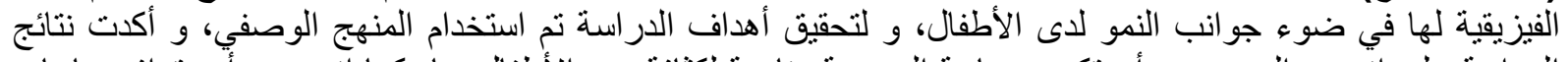

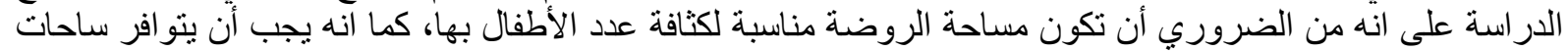

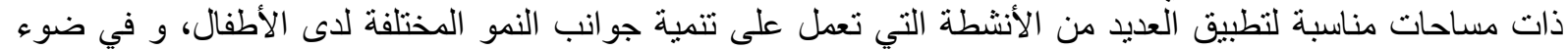

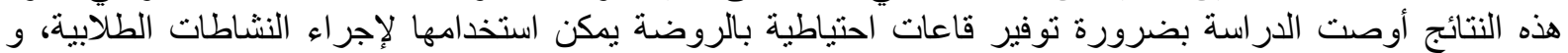

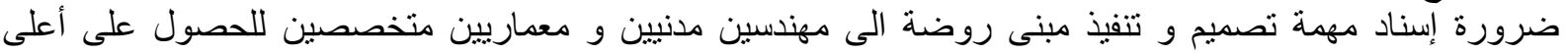

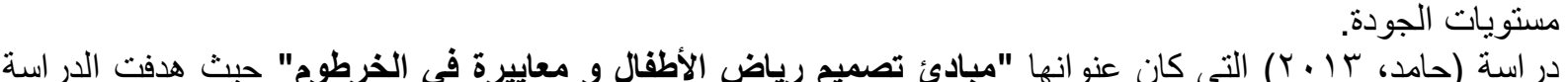

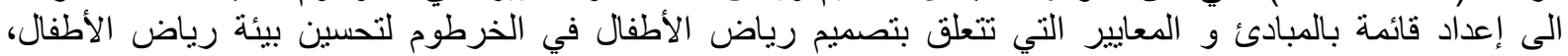

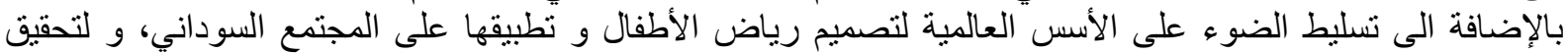

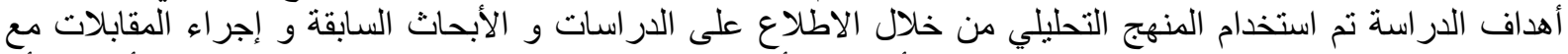

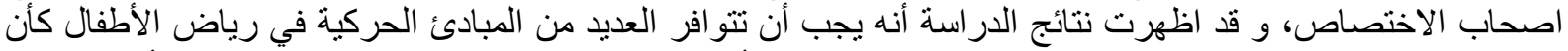

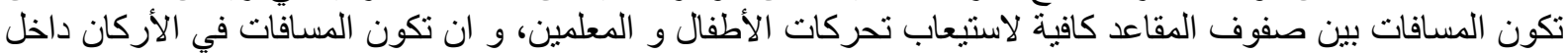

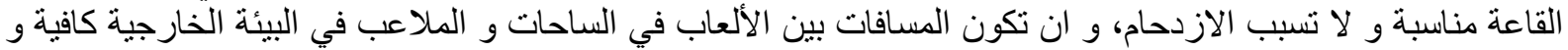

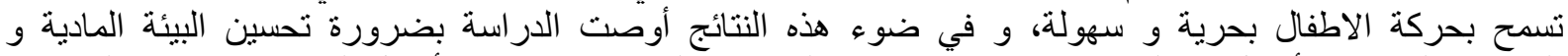

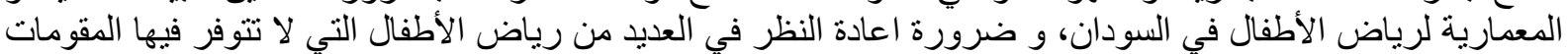
الأساسية و الضرورية لرياض لرياض الأطفال الأطفال.

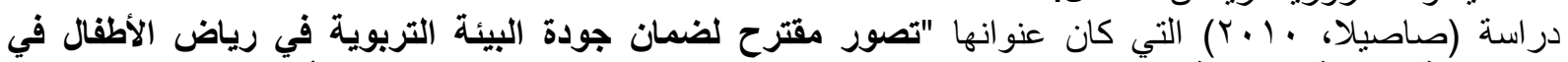

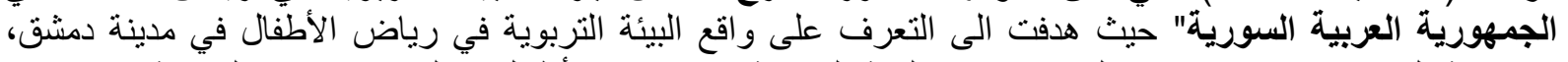

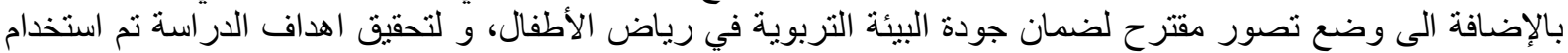

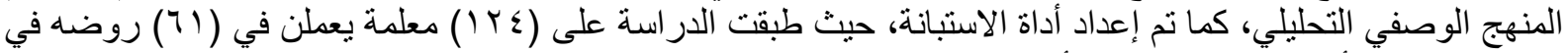

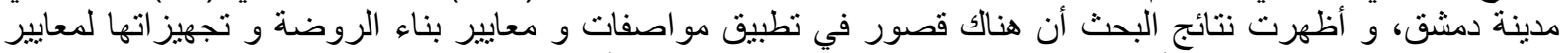

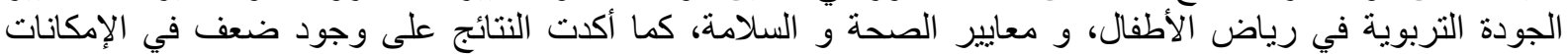

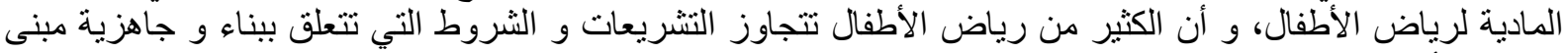

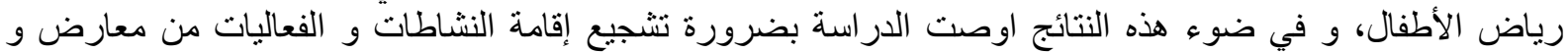

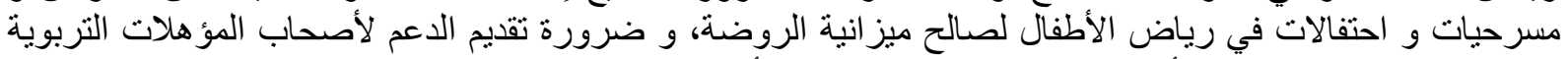

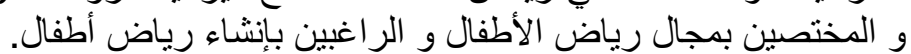

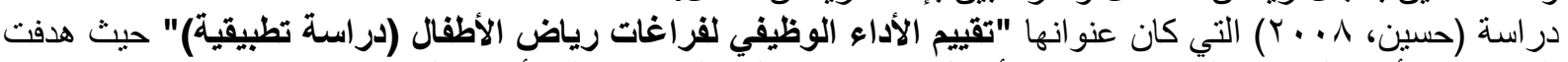

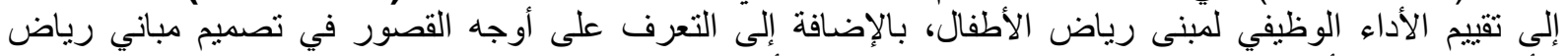

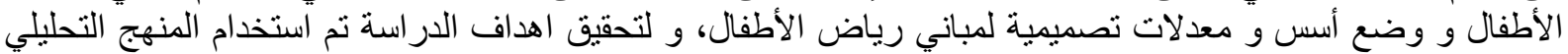

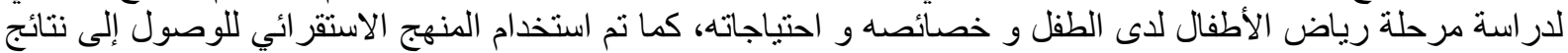

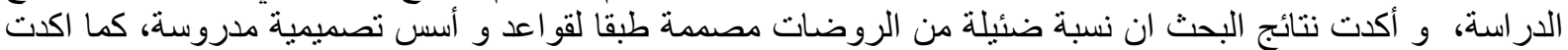

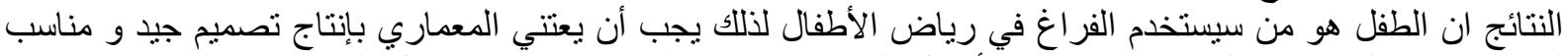

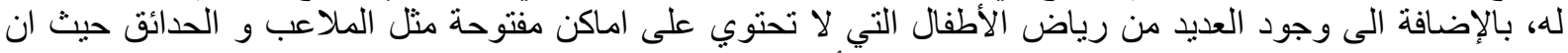
العديد منها عبارة عن وحدات سكنية استخدمت كرياض الاض أطفال.

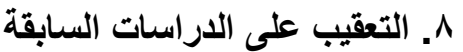

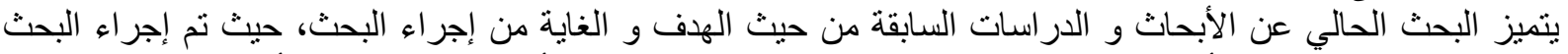

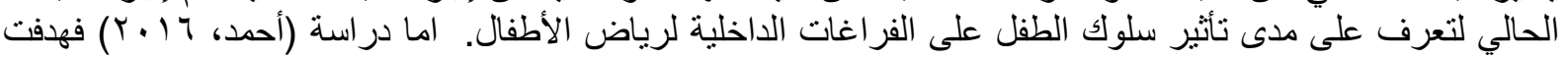

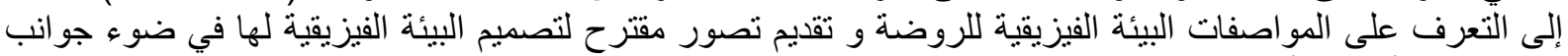

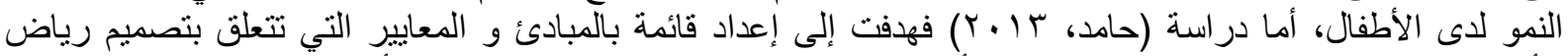

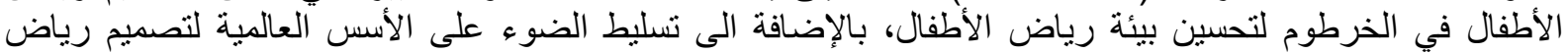

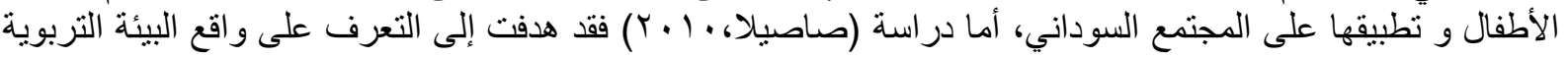




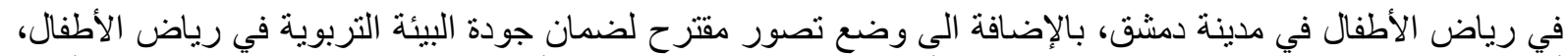

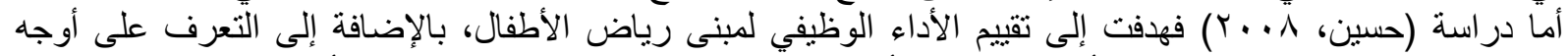

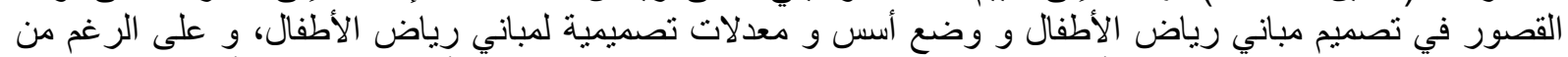

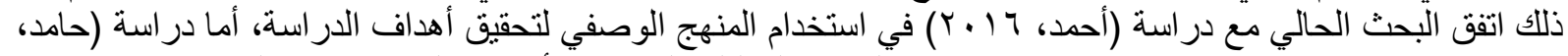

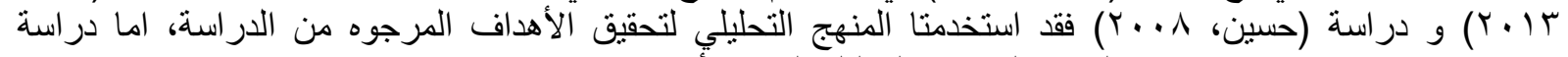

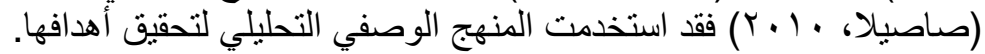

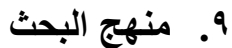

لتحقيق أهداف البحث التي تتمثل في تحديد ددى تأثير سلوك الطفل على الفراغات الداخلية لرياض الاطفال، و تسليط

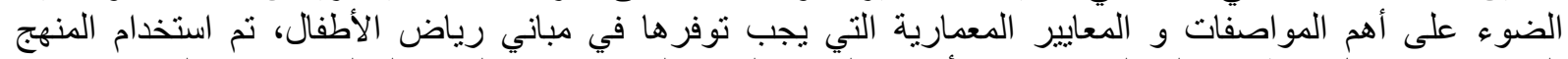

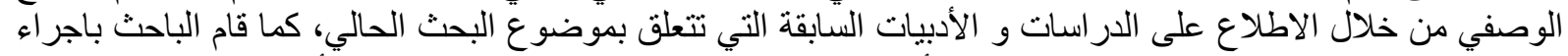

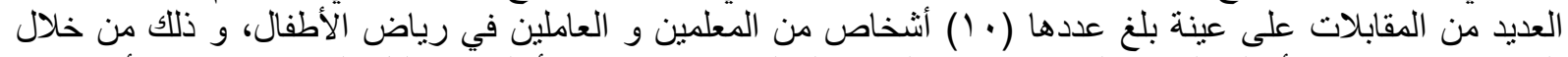

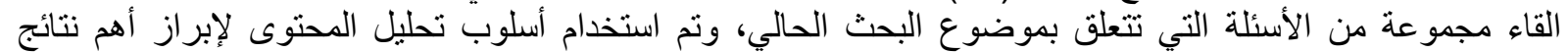

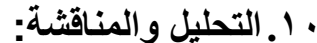

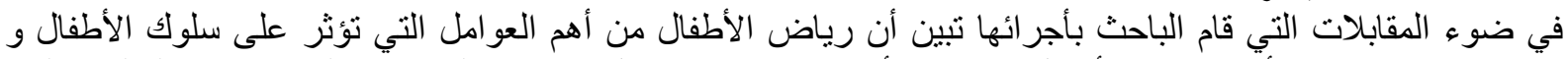

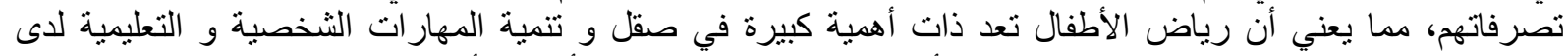

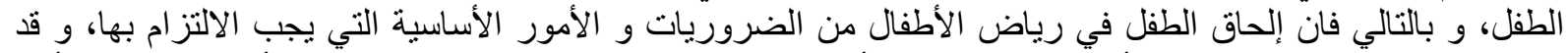

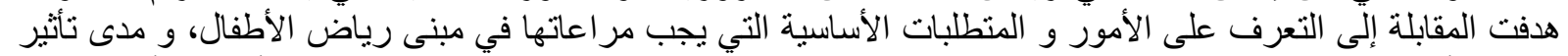

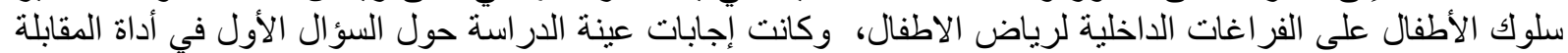

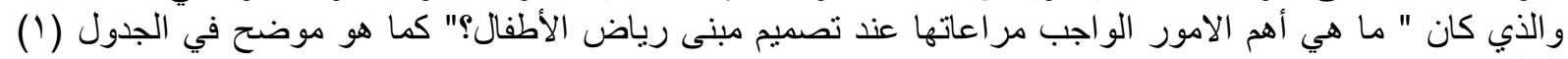

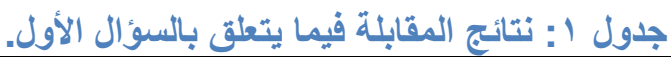

\begin{tabular}{|c|c|}
\hline ب مراعاتها عند تصميم مبنى رياض & 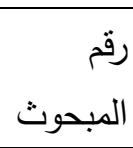 \\
\hline يفضن ان تصؤثر على مبلى أو الفراغات الداخلية لرياض الاطفال. يفال كدور ارضي، وذلك لتجنب السلالم التي & ( ) \\
\hline عند الاضطرار الى السلالم لابد من تؤخذ اعتبارات السلامة والامان للأطفال لتجنب المخاطر . & $(r)$ ? \\
\hline يجب مراعاة أن تكون السلالم قليلة في تصميم مبنى رياض الأطفال لضمان عدم تعرض الأطفال إلى & $(r)$ 阝 \\
\hline |لاحنياجات الخاصور التي يجب مراعاتها في تصميم المبنى أن يكون مصمح بحيث يخدم أصحاب ذوي & $(\varepsilon)$ ? \\
\hline الاخذ بعين الاعنبار مواد البناء في ارضية السلالم كتجنب المواد الناعمة لتجنب الانزلاق. & $(0)$ (0) \\
\hline |مراعات ارتفاع القائمة في السلالم واحترام مقياس الطفل. & ( ) \\
\hline معالجة الحواف في السلالم لخطورتها على الاطفال وتجنب السلالم افضل. & $(\mathrm{v})$ r \\
\hline المنحدرات ريما الحل الامتل للاتصال الراسي وتقلل من المخاطر التي يتعرض لها الطفل. & $(\wedge) \div$ \\
\hline تصميم حواف السلالم ( الدروة) بحيث لا يستطيع الطفل تسلقها. & $(9)$ ( ) \\
\hline تجنب اختلاف المنسوب في الفراغات الداخلية وذلك لسلامة الاطفال وكذلك مراعات لذو الاحتباجات & $(1 \cdot)$ e \\
\hline
\end{tabular}

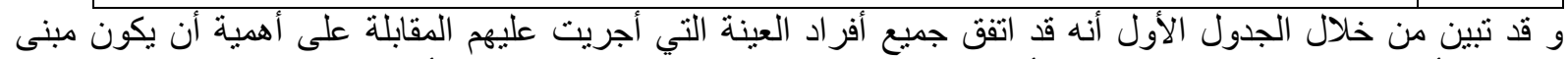
رياض الأطفال مكون من طابق واحد و ألا يتكون من عدة طو ابق و ذّلك لتفادي وقوع أبي من الحو ادث التي من الممكن 
أن يتعرض لها الأطفال أثناء صعود أو نزول الدرج، كما رأى البعض أنه من الضروري أن يتم مر اعاة الأطفال الذين

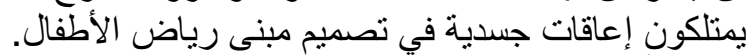

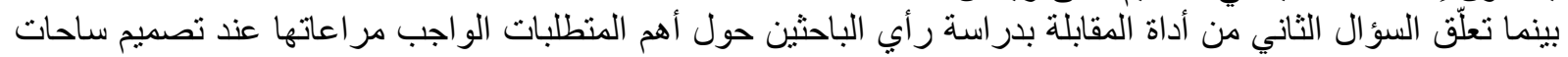
مبنى رياض الاطفال وتمثلت الإنجابات بالثنالي:

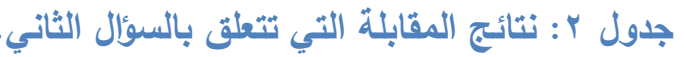

\begin{tabular}{|c|c|}
\hline الأطفال؟ الثوال الثاني: ما هي أهم المتطلبات الأساسية التي يجب مراعاتها عند تصميم ساحات مبنى رياض & الرقم \\
\hline يجب أن تكون الساحات كبيرة يتحرك بها الأطفال بكل أريحية. & (1) \\
\hline أن تكون المداخل الخارجية و الداخلية مصممة بطريقة تجذب الأطفال. & $(r)^{5}$ \\
\hline من الضروري أن تكون الساحات واسعة و مغطاة بالعشب الأخضر . & ( \\
\hline 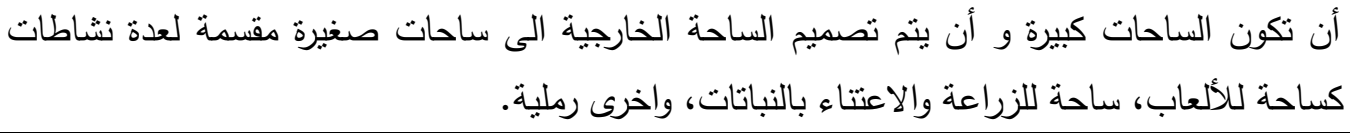 & $(\varepsilon)^{5}$ \\
\hline تكنون الأرم الأمور التي يجب مراعاتها في تصميم الساحات أن تكون واسعة تتسع لجميع الأطفال و أن & $(0)^{\beta}$ \\
\hline تتوع تغطية ساحات اللعب بالرمل او بمواد اسفنجية لسلامة الاطفال. & $(\tau)^{5}$ \\
\hline تجنب النباتات ذات الغصان الحادة والاشواك. & $(\mathrm{v})^{\mathrm{s}}$ \\
\hline يجب ان يكون اثاث الساحات كالكراسي وحاويات النفايات تحترم مقياس الطفل. & $(\wedge)^{\zeta}$ \\
\hline حديقة الطفل تساعد الاطفال على تعلم الزراعة والاعتتاء بالنباتات. & ()$^{8}$ \\
\hline بشكل يساعد المعلم على مراقبة الاطفال وذلك بتجنب الفراغات المنزوية والغير مرئية. & $(1 \cdot)^{5}$ \\
\hline
\end{tabular}

كما تبين من خلال الجدول (r) أنه من الضروري أن يكون المدخل الخارجي و الداخلي لرياض الأطفال مصمم بطريقة

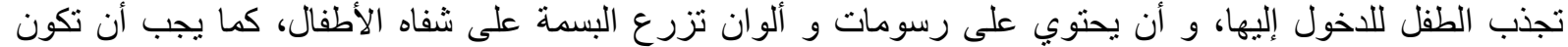

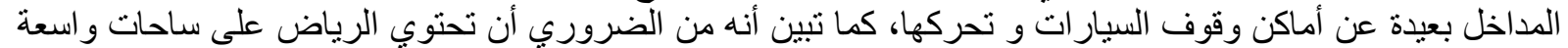

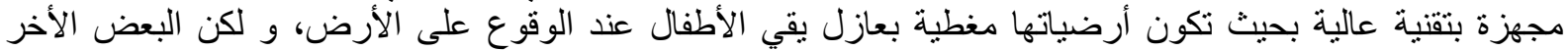

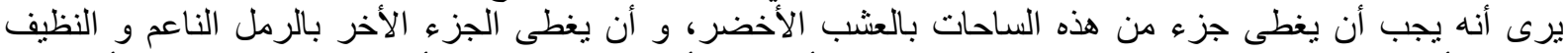

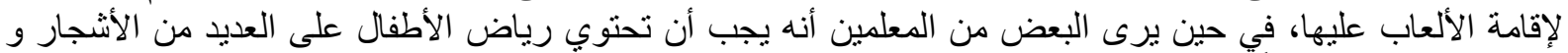

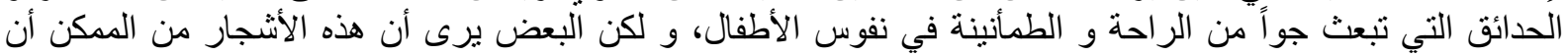

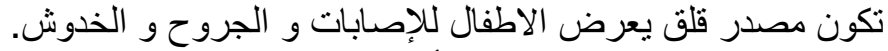

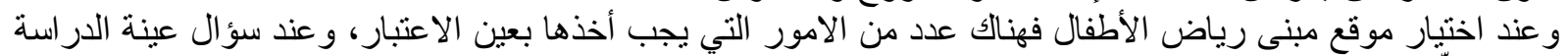
حولها تمثنّت إجاباتهم بالتالي: 
جدول ץ: نتائج المقابلة تتعلق بالسؤال الثالث.

\begin{tabular}{|c|c|}
\hline السؤال الثالث: ما هي أهم الأمور التي يجب مراعاتها عند اختيار موقع مبنى رياض الأطفال؟ & الرقم \\
\hline | يجب أن يكون المبنى بعيد عن الإزعاج و أماكن الازدحام. & $(1)$ ( \\
\hline | يفضل عدم تحديد الموقع على الثوارع الرئيسية السريعة وذلك لتجنب الازدحام المروري. & $(r)^{5}$ \\
\hline |لابد من توفر مواقف سبارات كافية لأولياء الامور ، وذلك لمرافقتهم الى مدخل الروضة. & $(\mathrm{r})$ ) \\
\hline |عدم توفر مواقف سبارات كافية يعد من العيوب التي تتسبب في انزعاج اولياء الامور. & $(\xi)^{\circ}$ \\
\hline أن يكون الموقع بعيد عن مصادر التلوث و الأماكن الصناعية. & $(0)$ ? \\
\hline أن تكون رياض الأطفال قريبة من الأماكن السكنية، لسهولة وصول الاطفال اليها. & (?) \\
\hline لا يهم كثيرا الموقع الأهم أن تتوفر جميع الاحتياجات و الضروريات التي يحتاجها الطفل. & $(\mathrm{v})^{5}$ \\
\hline | الاهتمام بالموقع العام من حيث التشجير وتتوع الارضيات والممرات الواسعة. & $(9)$ ( \\
\hline الاخذ بعين الاعتبار المسافة الكافية بين الثنارع ومدخل الاطفال. & (1.) \\
\hline
\end{tabular}

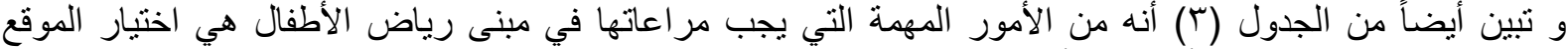

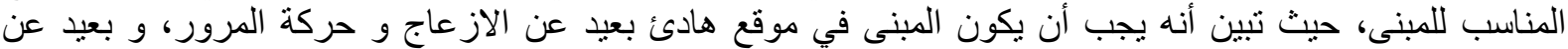

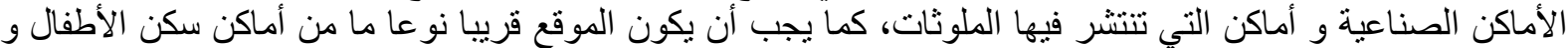

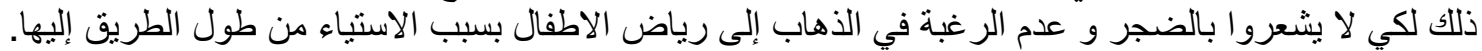

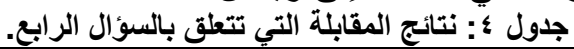

\begin{tabular}{|c|c|}
\hline الأطفال؟ الرابع: ما هي أهم الأمور التي يجب مراعاتها عذ تصميم الفراغات الداخلية في رياض & الرقم \\
\hline أن تتوافر التهوية و الإضـاءة الطبيعية. & $(1)$ ( \\
\hline يفضل التعامل مع الفراغات المفتوحة قدر الامكان. & (r) 5 \\
\hline | تحتوى على فراغ مخصص للإسعافات الأولية. & 5 \\
\hline أن تحتوى على دورات مياه كافية وتتتاسب مع مقياس الطفل. & (ई) \\
\hline أن تكون غرف النثاط مستطيلة الثكل، تتتاسب مع مقياس الطفل. & $(0)$ (0) \\
\hline أن تحتوى على ممرات واسعة تسهل حركة الأطفال خلالها. & (7) \\
\hline أن يكون الأثاث الموجود فيها مختار بعناية صحي و مناسب للاستخدام من قبل الأطفال. & $(\mathrm{v})^{5}$ \\
\hline التقليل قدر الامكان من الأعمدة و الزوايا الحادة التي تشكل مصدر قلق للأطفال. & $(\wedge)$ ? \\
\hline معالجة الارضيات بالموكيت او المواد الاسفنجية لحماية الطفل عند السقوط عل الارض. & $(q)$ ( ) \\
\hline تجنب اختلاف المناسيب لسلامة الاطفال. & 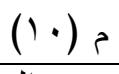 \\
\hline
\end{tabular}

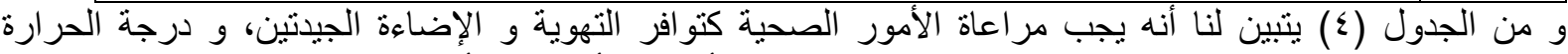

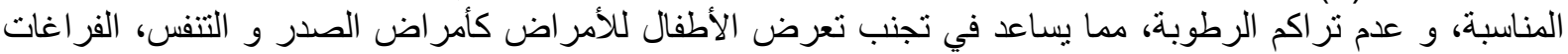

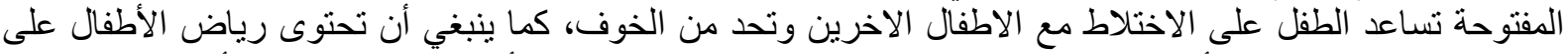

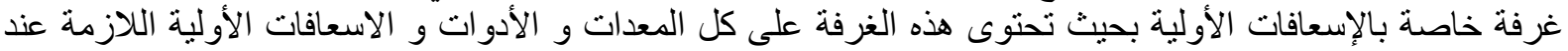

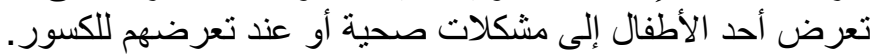

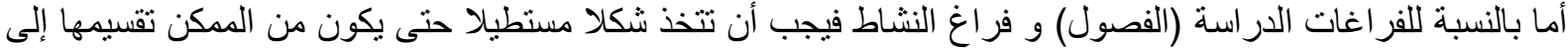

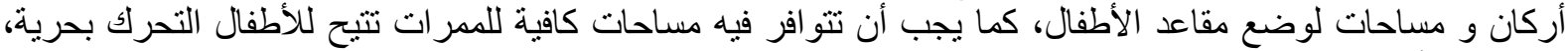

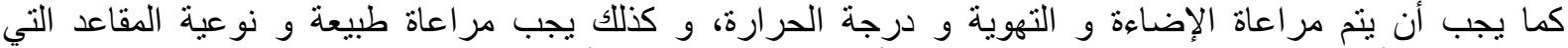

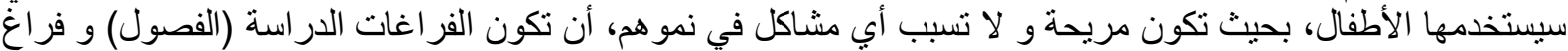

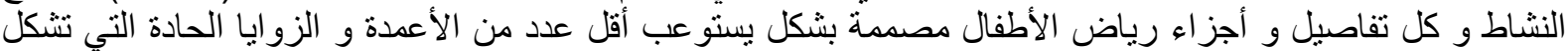

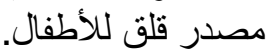




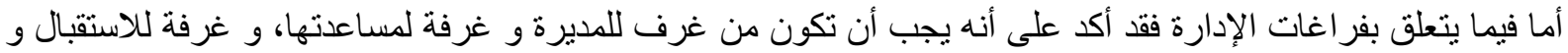

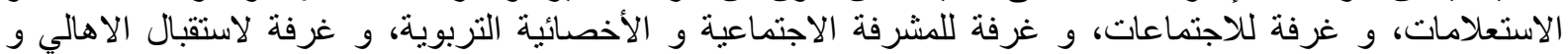

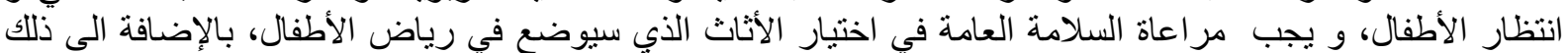

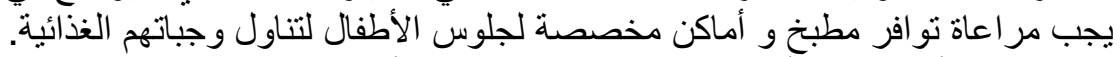

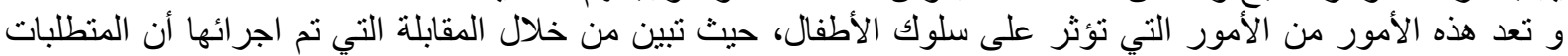

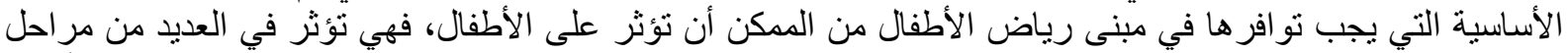

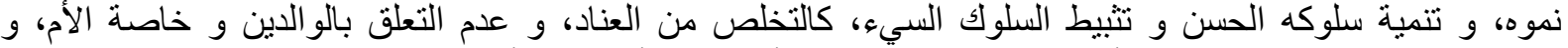

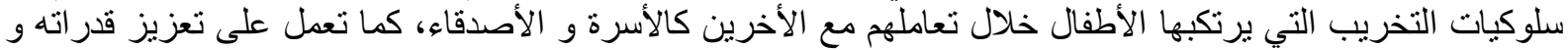

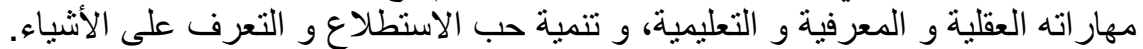

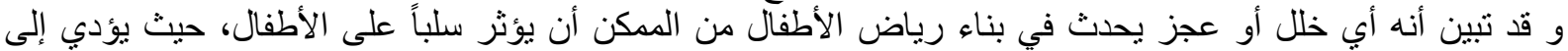

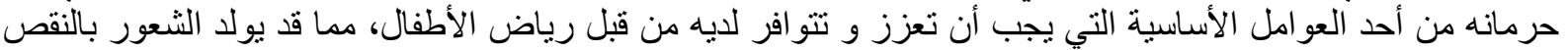
و انخفاض مستوى الذكاء لاءى الأطفال.

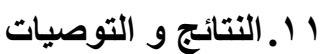

تلعب رياض الأطفال دورا مهما في توفير الأنشطة الإبداعية و الإثرائية التي تنمي السلوك لدى الدئ الطفل تلبي حاجاته

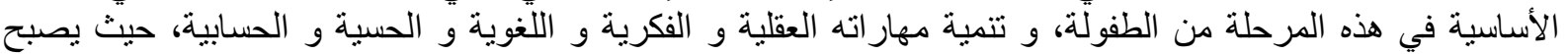

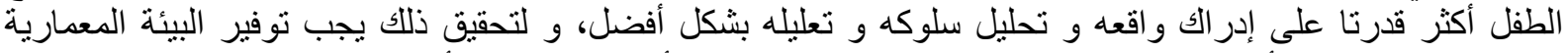

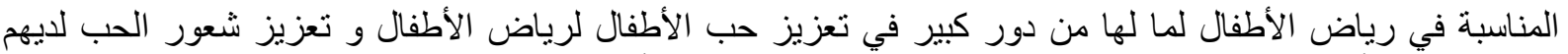

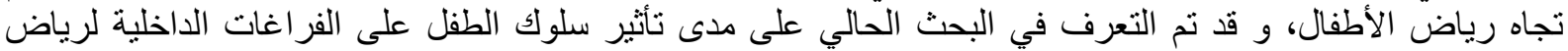

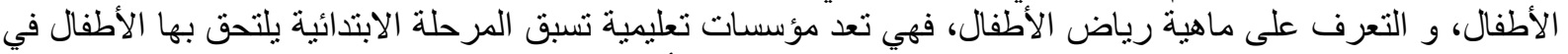

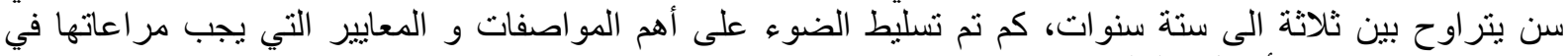

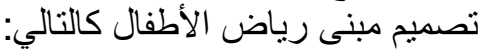

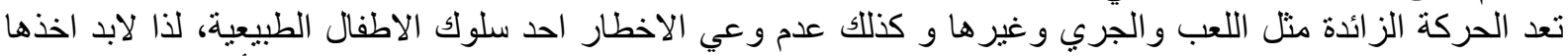

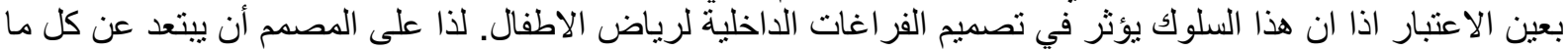

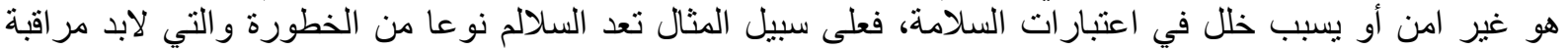

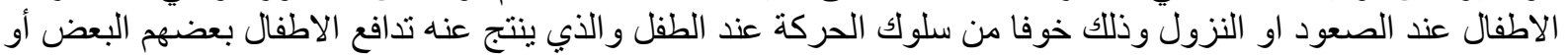

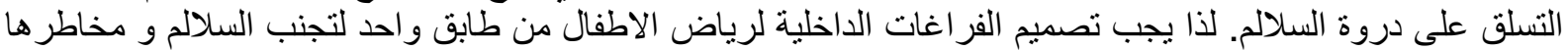
التي يمكن ان تؤثر على سلامة الاطفال.

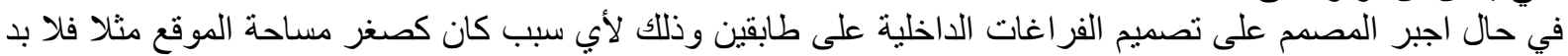

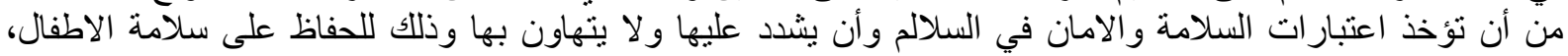

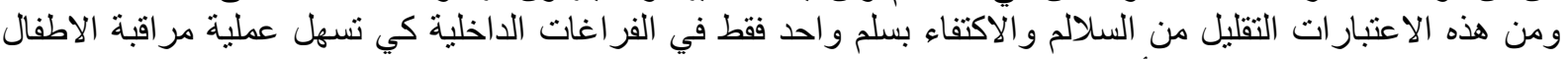

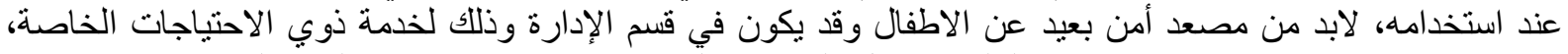

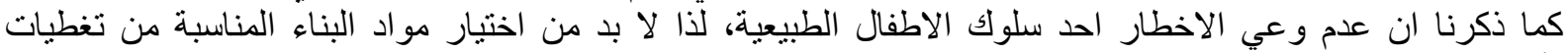

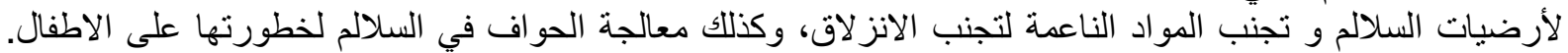

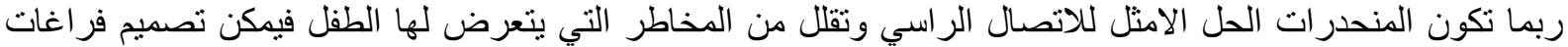

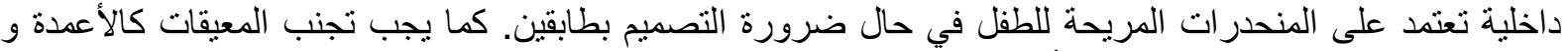

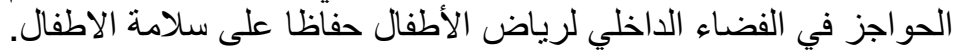

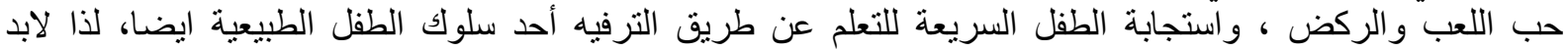

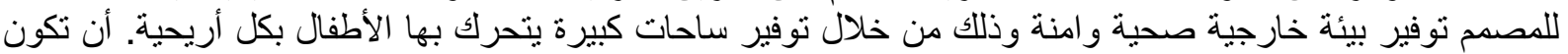

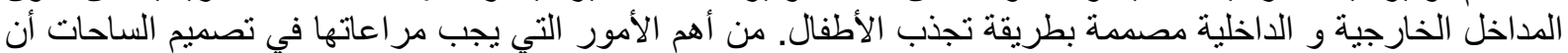

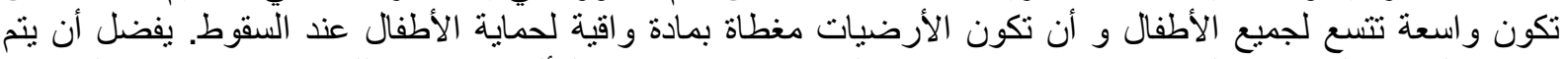

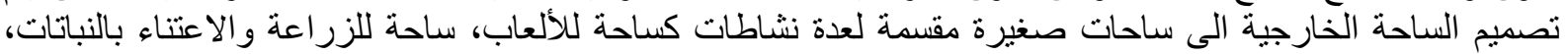

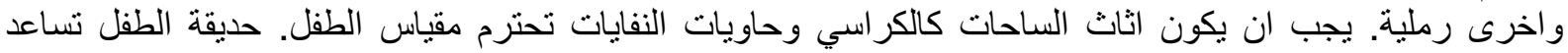

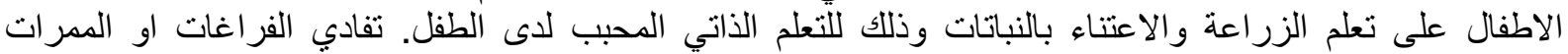

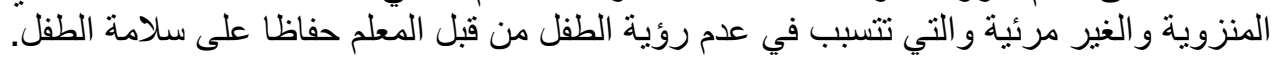

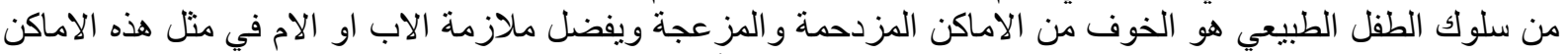

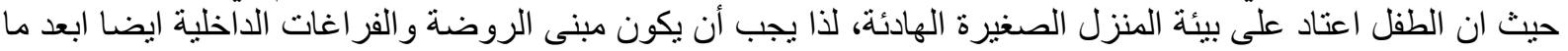

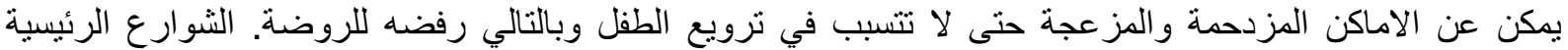

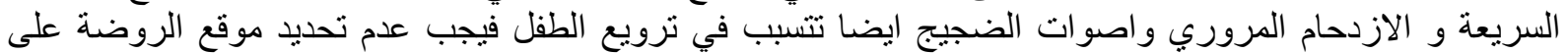

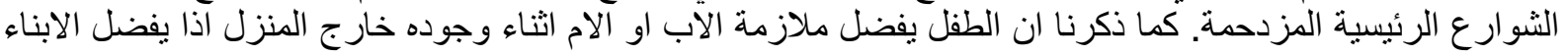




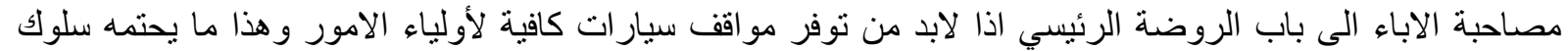

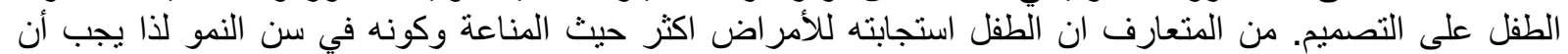

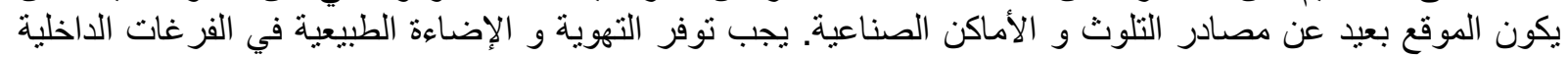

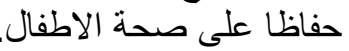

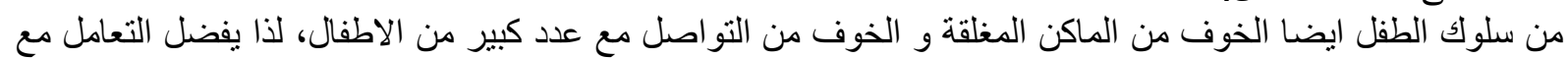

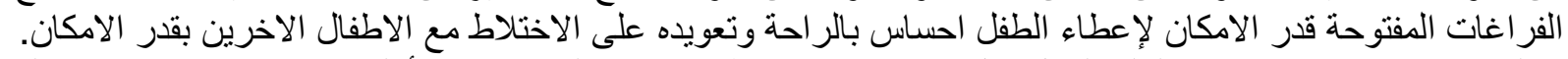

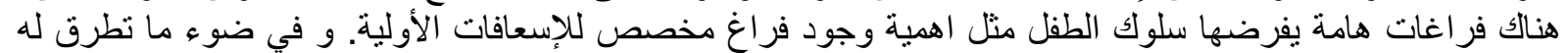

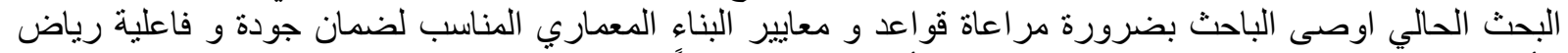

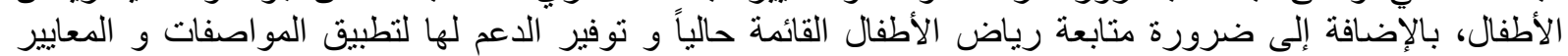

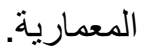

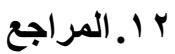

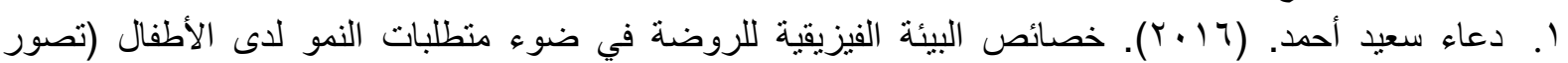

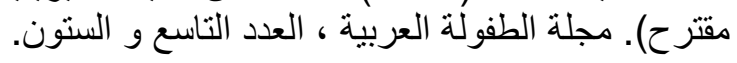

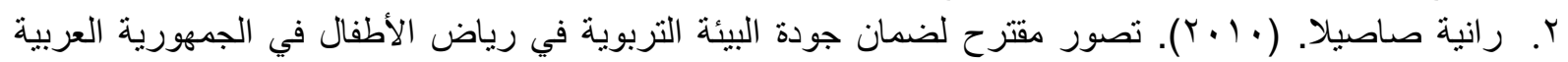

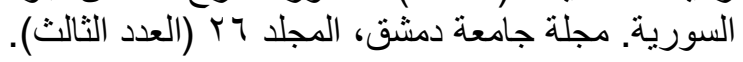

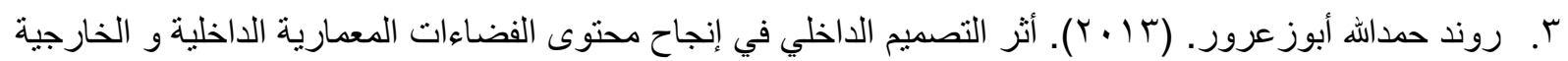

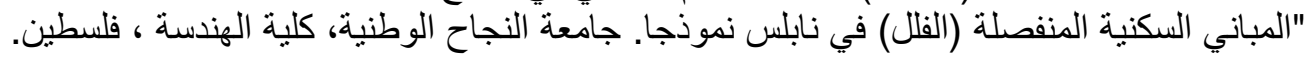

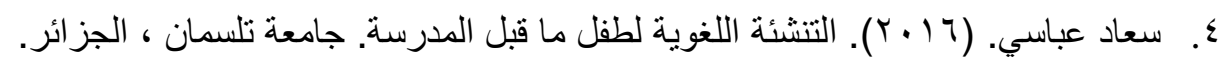

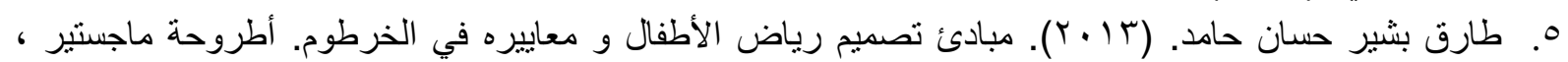

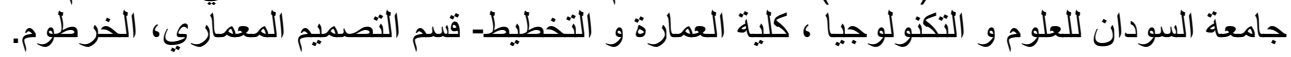

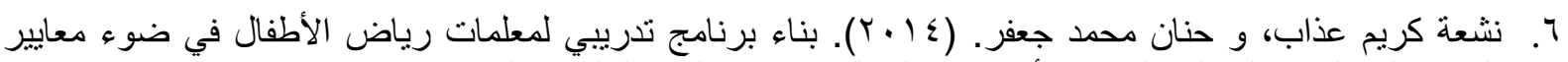

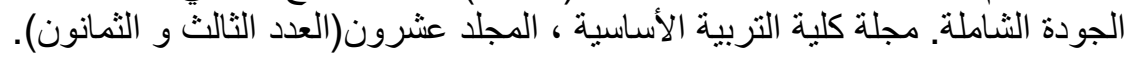

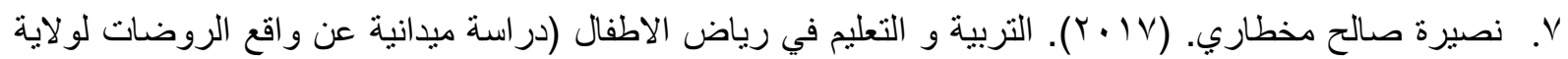

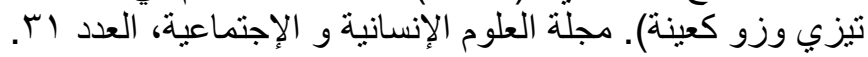

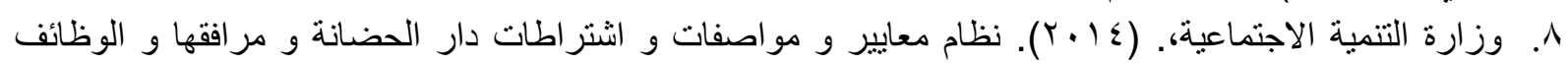
فيها. مملكة البحرين.

9. و ولاء حسين حسين. (1 . ㄷ). تقييم الأداء الوظيفي لفر اغات رياض الأطفال (در اسة تطبيقية). جامعة عين شمس، كلية الهندسة ، جمهورية مصر العربية. 